\title{
Matched-Guise Experiment and Its Application to Measure Uyghur Trilinguals' Language Attitudes
}

\author{
Huaying Chen \\ College of Foreign Languages \\ Xinjiang Normal University \\ Urumqi, Xinjiang, China \\ e-mail: chenhuaying@163.net
}

\author{
Chuanfeng Cao \\ Xinjiang Medical University \\ Urumqi, Xinjiang, China \\ e-mail: karlcao@163.com
}

\begin{abstract}
Matched-guise experiment has been proved as a powerful attitudinal research tool. This paper is about the language attitudes that Uyghur university students in Xinjiang have towards Uyghur (their mother tongue), Chinese (their second language), and English (their foreign and third language). The language attitudes of 220 Uyghur undergraduate students from three universities in Urumqi were investigated using the matched-guise experiment. This study finds that although there are statistically significant differences between their attitudes towards Uyghur, Chinese and English, Uyghur university students hold overall favorable and positive attitudes towards all the three languages, and they give Uyghur the highest rating.
\end{abstract}

Keywords-matched-guise experiment; language attitude; Uyghur; language policy

\section{INTRODUCTION}

Xinjiang lies in the northwest part of China. It has over 20 ethnic minorities, among which, Uyghur has the largest population. Both Chinese and Uyghur are the official languages used in the region of Xinjiang. In the past 20 or so years, minority language-Chinese bilingual education for ethnic minority students has been greatly enhanced here. So Uyghur university students are all bilinguals of Uyghur and Chinese. English is not a required subject for the ethnic minority schools, but in some universities in Xinjiang the ethnic minority students have started to learn English as a foreign and third language in very recent years.

Attitudes can be viewed as comprising three components: cognitive, affective, and behavioral [1]. As summarized by Garrett, Coupland, and Williams [2], this view posits language attitudes are cognitive in that they comprise beliefs about the world (e.g. proficiency in English will lead to better jobs and upward social mobility). They are affective in that they involve feelings about the language. They are also 'systematically linked to behavior, because they predispose us to act in a certain way' [2]: for example, to learn a particular language. Because of the dominance of the official discourse in shaping how and what people think about language [3], our analysis also takes into consideration the language policy in Xinjiang and China, with a particular focus on the language attitudes of Uyghur university students.

The methods used in past studies for measuring language attitudes can be broadly classified into three groups: content analysis of societal treatment, direct measurement and indirect measurement. Each inevitably has its own strengths and weaknesses. One of the best illustrations of the type of approach of content analysis is Fishman's language loyalty in the United States in which trends in the maintenance and shift of ethnic languages are examined in terms of detailed analyses of laws/policies regarding language use, the numbers of language users and the proportions of language use in various domains [4]. The direct method requires respondents to respond to a questionnaire or interview questions that simply ask their opinion about certain languages, speakers of a particular language or a languageplanning program.

When indirect methods are used, the respondents are not aware that their language attitudes are being investigated. The most frequently used indirect method in investigating language attitude is the "matched-guise technique" developed by Wallace Lambert and his associates [5].

The procedure of matched-guise experiment was summarized by Fasold [6]. A number of bilingual speakers who are fluent in the two languages under investigation are asked to read exactly the same passage in different languages. The reading is tape-recorded and the passage is arranged in such a way that each passage seems to be read by a different individual. Bilingual listeners are asked to judge the recordings on the basis of voice cues alone and rate the speakers on various characteristics, such as intelligence, social class, and likeability. Since each person has provided samples of the two languages, if the same person is rated differently in different "guises", one can possibly conclude that it is the different attitudes towards languages that account for it.

In Lambert's original matched-guise study [5], his subjects produced more positive social ratings for reading with standard pronunciation or upper class speech than for readings with lower class or ethnic varieties. Lambert conducted a series of such experiments in North America [5]. The results led him to conclude that the stereotyped impressions that members of an ethno linguistic group held for another group could be revealed by speech cues alone. According to Lambert, people unconsciously translate their social attitude towards languages (language varieties) into differential judgments of a speaker's personality or status. This technique appears to reveal more valid reactions than direct questionnaires do.

The rating scale most often used with the matched-guise technique is a semantic differential scale. In these scales, the opposite extremes of a trait (friendly vs. unfriendly; intelligent vs. unintelligent) are designated at either end and 
there are a number of blank spaces between them. If the listener feels the sound on the tape is extremely unfriendly, s/he would place a mark on the line closest to the word "unfriendly".

In this paper, we address the following question: What are the attitudes of Uyghur university students towards a speaker using their mother tongue, a speaker using Chinese, and a speaker using English?

\section{MEthodOLOGY}

\section{A. Subjects}

The subjects consisted of 220 Uyghur university students from three universities in Urumqi, the capital city of Xinjiang. There were 74 male students and 146 female students. They ranged in age from 19 to 22 .

According to their self-reporting, around 20\% of them passed Band 9 of HSK (HSK is a Chinese proficiency test which is designed to test those people whose native language is not Chinese) or above level, $40 \%$ of them passed Band 8 of HSK, $30 \%$ of them passed Band 7 and $10 \%$ of them passed Band 5 and Band 6. So from the figures we know that most of the subjects' Chinese level lies in the medium level.

Among these subjects, $65 \%$ of them stated that they were exposed to English after they came into university; about $20 \%$ of them stated that they started to learn English from secondary school; 15\% of them started to learn English from primary school.

\section{B. Stimulus Speech Samples}

The study used the standard matched-guise technique. One female speaker was used to provide the stimulus for the study (Table 1). Subjects were asked to evaluate three recorded speech samples of the same speaker, but they were not informed that the same speaker was used in all three recordings.

TABLE I. STIMULUS SPEAKER

\begin{tabular}{|c|c|c|c|c|}
\hline Gender & Ethnicity & Age & Occupation & $\begin{array}{c}\text { Educational } \\
\text { Background }\end{array}$ \\
\hline Female & Uyghur & 44 & Academic & Postgraduate \\
\hline
\end{tabular}

The stimulus speaker is a native of Uyghur. She was born and had her primary and secondary education in Xinjiang, and had her university education in Shanghai with the major of English. She is now teaching English in a university in Xinjiang. So she is a qualified speaker for all the three languages.

The stimulus speaker was asked to make three recordings with Pratt software: one recording in Uyghur, one in Chinese and the third one in English. The material was a humorous English short story, which was abstracted from Mini English published by Oxford University. The short story contains 74 English words, the translated Chinese version contains 124 Chinese words, and the translated Uyghur version contains 62 Uyghur words. It took about 40 seconds to read this story. This short story was simple and easy to understand. It was so humorous that the subjects would not be bored even though it was read three times respectively in Chinese, English and Uyghur.

\section{Traits}

The subjects listened to Speaker A (Chinese) first and then rated the speaker on 8 different personality traits using a 7-point Likert scale as follows, where (1) represented the lower end (e.g. Not friendly) and (7) represented the higher end (e.g. Friendly): Friendly-Not friendly, Cordial-Not cordial, Passionate-Not passionate, Polite-Not polite, Trustworthy-Not trustworthy, Educated-Not educated, Respectable-Not Respectable, Humorous-Not humorous.

The subjects then did the same to Speaker B (English) and Speaker C (Uyghur).

The results were analyzed statistically by using software SPSS14.0.

\section{RESULTS AND DISCUSSION}

TABLE II. OVERALL DIFFERENTIATION OF EVALUATIONS ON THE THREE GUISES (ONE-WAY ANOVA)

\begin{tabular}{|c|c|c|}
\hline Traits & $F$ & P-value \\
\hline Friendly & 18.303 & .000 \\
\hline Cordial & 23.396 & .000 \\
\hline Passionate & 12.397 & .000 \\
\hline Polite & 24.389 & .000 \\
\hline Trustworthy & 29.904 & .000 \\
\hline Educated & 11.571 & .000 \\
\hline Respectable & 21.640 & .000 \\
\hline Humorous & 29.970 & .000 \\
\hline
\end{tabular}
significant differences between evaluations of the three guised speakers with respect to these eight traits $(p=.000<0.05)$. In order to explore further, we conducted the multiple comparisons between these three guises, as is shown in Table 3.

From Table 3 , it can be clearly seen that significant differences $(p<0.05)$ are found between the evaluation of the Uyghur guise speaker and the evaluation of the Chinese guise speaker in terms of all the rated traits. There is also significant differences between evaluation of the guised Uyghur speaker and evaluation of the guised English speaker in terms of all the rated traits $(p<0.05)$. The Uyghur guised speaker is rated the highest among the three guised speakers.

There are significant differences between the evaluation of the guised Chinese speaker and the evaluation of the guised English speaker in regard to the traits of being polite $(p=.020<0.05)$ and being humorous $(p=.000<0.05)$. The students rate the guised Chinese speaker more polite than the guised English speaker, and they evaluate the guised English speaker more humorous than the guised Chinese speaker. No significant differences are found between Chinese and English in terms of other traits ( $\mathrm{p}>0.05)$. 
TABLE III. OVERALL DIFFERENTIATION OF EVALUATIONS ON THE THREE GUISES (MULTIPLE COMPARISONS)

\begin{tabular}{|c|c|c|c|c|c|c|}
\hline Traits & $\begin{array}{c}\text { Uyghur } \\
\text { and } \\
\text { Chinese } \\
\text { (mean } \\
\text { difference) }\end{array}$ & Sig. & $\begin{array}{c}\text { Uyghur and } \\
\text { English } \\
\text { (mean } \\
\text { difference) }\end{array}$ & Sig. & $\begin{array}{c}\text { Chinese } \\
\text { and } \\
\text { English } \\
\text { (mean } \\
\text { difference) }\end{array}$ & Sig. \\
\hline Friendly & .7288 & .000 & .5805 & .000 & -.1483 & .138 \\
\hline Cordial & .7669 & .000 & .7754 & .000 & .0085 & .937 \\
\hline Passionate & .6483 & .000 & .4873 & .000 & -.1610 & .163 \\
\hline Polite & .6483 & .000 & .9195 & .000 & .2712 & .020 \\
\hline Trustworthy & .9958 & .000 & .7924 & .000 & -.2034 & .067 \\
\hline Educated & .4746 & .000 & .5932 & .000 & .1186 & .287 \\
\hline Respectable & .6949 & .000 & .7924 & .000 & .0975 & .372 \\
\hline Humorous & 1.3814 & .000 & .8559 & .000 & -.5254 & .000 \\
\hline
\end{tabular}

Figure 1 indicates the subjects' ratings on the three guises, in which the horizontal axis represents the 8 rating items; the vertical axis represents the mean scores. The three curves represent the results of rating on Uyghur, Chinese and English guise speaker respectively. The means for all the traits of the three guises are higher than or equal 3.5, the middle point of the 7-point Likert scale.

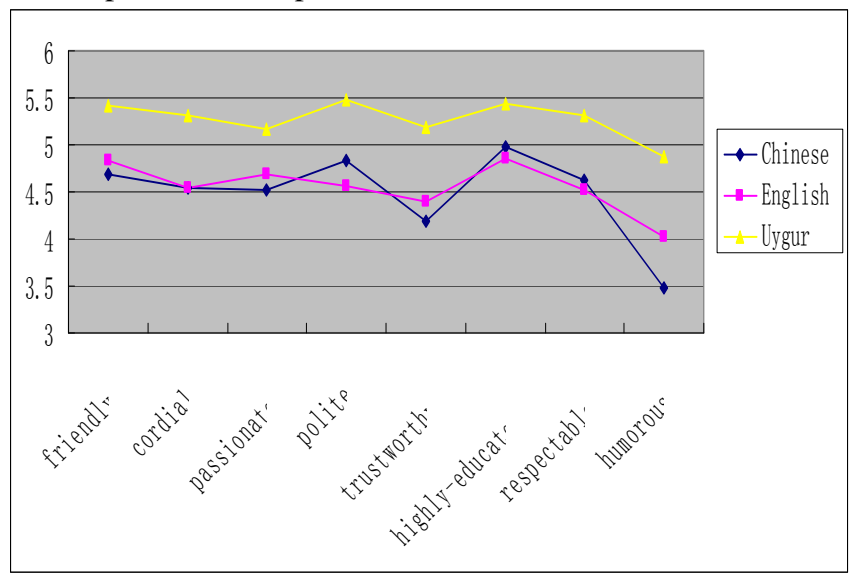

Figure 1. General evaluation on the 8 traits among Uyghur, Chinese and English.

For all eight traits evaluated, there is a striking trend of higher evaluation of the traits in the Uyghur guise speaker. The evaluation to Uyghur guise speaker is on the top of the whole chart. The matched-guise test documents subconscious language attitudes. Uyghur students' reactions to the speech of Uyghur guise speaker show their attitude towards Uyghur language. The subjects rate Uyghur high not only from the affective aspect but also from the status aspect. They demonstrate strong in-group loyalty to Uyghur language and cultural identity. Uyghur people are proud of their language and their ethnicity.

The rating trends of evaluation to Chinese guise speaker and to English guise speaker are similar. The evaluations of these two guised speakers are all under the evaluation to Uyghur guise speaker. Uyghur is their mother tongue and their language of instruction in primary and secondary schools. Chinese is taught as a subject at schools. Uyghur use Chinese when they communicate with non-Uyghur people. It is understandable that the evaluation to Chinese is lower than to Uyghur. English is taught as a foreign language for the students. Most Uyghur university students are exposed to English only after they have entered the universities. They seldom use it in their daily life.

There exists crossing patterns between the rating of Chinese and English at some points. Chinese speaker is slightly higher than English speaker in traits of being polite, highly educated and respectable. The rating of English guise speaker is slightly higher than the guised Chinese speaker in traits of being friendly, passionate, trustworthy and humorous. With the opening of our country and Xinjiang to the world, the students are accessible to English movies. They get to know about English-speaking people mostly from movies and TV. They are impressed mostly by Englishspeaking people's humor. Therefore they evaluate English guise speaker more humorous than Chinese guise speaker.

On the whole, it can be said that the subjects in general have overall positive attitudes towards all the three languages.

\section{CONCLUSION}

Significant differences are found between the evaluation of the Uyghur guise speaker and the evaluation of the Chinese guise speaker, and between the evaluation of the guised Uyghur speaker and the evaluation of the guised English speaker in terms of all the rated traits. The Uyghur guised speaker is rated the highest among the three guised speakers. This demonstrates that the subjects have strong affection for the Uyghur language. There are significant differences between the evaluation of the guised Chinese speaker and the evaluation of the guised English speaker in regard to the traits of being polite and being humorous. The students rate the guised Chinese speaker more polite than the guised English speaker, and they evaluate the guised English speaker more humorous than the guised Chinese speaker. No significant differences are found between Chinese and English in terms of other traits.

The subjects have overall positive attitudes towards all the three languages. The Uyghur students have more positive attitudes towards Uyghur than Chinese and English respectively, which shows their emotional identification with their mother tongue and the language group. The Uyghur students are also attached to Chinese because Chinese is an important national language in China and another official language in Xinjiang and they have learned the Chinese as a subject in schools since their childhood. Although they are learning English as a foreign language, the Uyghur students show their favorable and positive attitude also towards English. We witness in Xinjiang that Uygur students have a great interest in the language of English because of its international status, and the enthusiasm for learning English among Uyghur people is increasing recently. 


\section{ACKNOWLEDGMENT}

This work is supported by Xinjiang Projects of Humanities and Social Science Research from the Ministry of Education of China (10XJJA740001).

\section{REFERENCES}

[1] J. Edwards, "Language attitudes and their implication among English speakers," in Attitudes towards language variation, E.B. Ryan and H. Giles, Eds. London: Edward Arnold, 1982, pp. 20-33.
[2] P. Garrett, N. Coupland and A. Williams, Investigating language attitudes: Social meanings of dialect, ethnicity and performance. Cardiff: University of Wales Press, 2003.

[3] W. D. Bokhorst-Heng, “Debating Singlish”, Multilingua, vol. 24, issue 3, 2005, pp. 185-209.

[4] J. A. Fishman, Language Loyalty in the United States. The Hague: Mouton, 1966.

[5] W. E. Lambert, “A social psychology of bilingualism”, Journal of Social Issues, vol. 23, issue 2, 1967, pp. 91-99.

[6] R. Fasold, The Sociolinguistics of Society. Oxford: Basil Blackwell, 1984. 